\title{
MELINDROSAS E ALMOFADINHAS: relações de gênero no Recife dos anos 1920
}

\author{
Hugo Augusto Vasconcelos Medeiros*
}

\section{Resumo}

O objetivo deste artigo é observar a configuração das relações de gênero no Recife dos anos 1920, a partir de dois personagens-estereótipos que figuravam nos discursos dos periódicos da época: a melindrosa e o almofadinha. Estes personagens exemplificavam uma abertura na forma de se comportar, normatizada nas relações de gênero, o que os levava a ser alvo de críticas e piadas. Para empreender este estudo, analisarei dois periódicos de tipologia diferente, o Jornal do Commercio e o semanário a Pilhéria, com base na sociologia configuracional de Norbert Elias, na análise do discurso e nas teorias sobre gênero. Desta forma, espero contribuir para as discussões acerca da categoria gênero, acrescentando elementos históricos que permitam rever preconceitos atuais.

Palavras-chave: Relações de Gênero. Imprensa. Discurso.

\section{Introdução}

Propomo-nos, neste artigo, observar a configuração das relações de gênero no Recife dos anos 1920, a partir da análise de dois personagens que figuravam nos discursos dos periódicos da época: a melindrosa e o almofadinha. Procuraremos perceber as relações que se estabeleciam na rede social da imprensa - formada basicamente por jornalistas e leitores - em contato com estes dois personagens. Que motivações que levavam jornalistas e leitores a criticar/elogiar estes dois personagens, e como os diferentes segmentos da imprensa construíram seus discursos sobre eles, utilizando-se de recursos estilísticos distintos, sendo o humor, entretanto, uma pedra angular, que reforçou a identificação destas personagens em caricaturas estereotipadas. Nossa análise estará centrada nas fontes primárias, que nos permitirão construir conclusões mediadas pelas discussões teóricas presentes em A sociedade

\footnotetext{
* Mestre em História pela Universidade Federal de Pernambuco. Professor do Centro de Educação a Distância e Ensino Continuado. Professor da Universidade Estadual do Vale do Acarajú. Pesquisador do Centro de Excelência em Tecnologia de Software do Recife. E-mail: hugoavmedeiros@hotmail.com
} 
dos indivíduos, de Norbert Elias, em especialmente com relação ao conceito de contexto funcional (ou rede de funções) ${ }^{1}$ (ELIAS, 1994, p. 22-23; 30; 35).

Com este objetivo, selecionamos dois periódicos recifenses, de duas tipologias distintas: um jornal, o Jornal do Commercio; e um semanário, a revista A Pilhéria.

Os jornais, por saírem todos os dias, estabeleciam uma relação mais breve com as notícias, que tinham de ir às suas páginas “fresquinhas”, dia após dia. Por outro lado, gozavam do prestígio de uma tipologia de imprensa já assentada na memória e na vida dos recifenses.

Os semanários - e a Pilhéria era à época o mais importante deles - tinham a seu lado a linguagem moderna, as páginas ilustradas, o formato menor, que lhes permitiam ser carregados Recife afora e a periodicidade semanal, com matérias sobre notícias degustadas e revistas ao longo de sete dias. Assim, a Pilhéria faz parte das "revistas ilustradas ou de variedades”, que, segundo Luca, tiveram um enorme surto durante o início do século 20, incluindo em suas páginas de acontecimentos sociais e crônicas a poesias, jogos e charadas (LUCA, 2005, p. 121).

A análise deste tipo de fonte impõe uma limitação incidental, que, no entanto, deve estar clara para os(as) pesquisadores(as): os jornais eram produzidos no início do século 20 por membros das classes médias urbanas como um instrumento para (1) divulgar coisas do cotidiano destas classes, e (2) como espaço para os(as) intelectuais publicarem seus textos, uma vez que o mercado editorial era pouco desenvolvido e bastante restrito.

Logo, um estudo histórico dos periódicos atinge uma parcela pouco significativa, em termos quantitativos, da população recifense da época. Muito embora em 1920 mais da metade da população recifense soubesse ler e escrever (IBGE, 1936) e os preços do jornal avulso e os de um semanário custassem menos da metade do ingresso mais barato do cinema, é extremamente difícil perceber até onde se estendiam aqueles que realmente compravam, liam e discutiam os jornais.

Ademais, não nos esqueçamos de que os populares ${ }^{2}$ quase não “davam as caras” nos jornais e, quando o faziam, era geralmente nas "páginas policiais”, como uma espécie de

\footnotetext{
${ }^{1}$ Elias emprega o termo “contexto funcional” como um "tecido de relações móveis [...] [com] uma estrutura muito específica”, cujo “caráter específico não é criação de indivíduos particulares” (1994, p. 22), nem algo externo a eles, mas produto de uma série dinâmica de relações construídas dia-a-dia, que atribuem aos indivíduos uma gama de funções a ser escolhidas/desempenhadas por eles. As ligações (relações) na rede formam "um sistema de tensões para o qual cada fio isolado concorre, cada um de maneira um pouco diferente, conforme seu lugar e função na totalidade da rede. A forma do fio individual se modifica quando se alteram a tensão e a estrutura da rede inteira” (ELIAS, 1994, p. 35).
} 
exemplo de um comportamento indigno de ser seguido pelas pessoas "civilizadas”. Isso não acontecia somente com os populares, mas com qualquer outro grupo (como as mulheres) que, dentro do grande e mais abrangente conjunto de redes que era a sociedade pernambucana, gozasse de menos status/poder social.

Antes de seguir para a análise empírica dos periódicos, contudo, devemos realizar uma breve discussão acerca da categoria "gênero” que norteará este artigo.

“Gênero” é uma ferramenta de análise que utilizaremos aqui de forma semelhante à proposta por Joana Maria Pedro, para quem, quando falamos em gênero, “estamos nos referindo a uma categoria de análise, da mesma forma como quando falamos de classes, raça/etnia, geração” (2005, p. 78); deve ser compreendida, portanto, a partir de uma análise relacional, que perceba as interações entre os indivíduos que se identificam como pertencentes a um gênero, em sua interação consigo mesmos e com outros indivíduos, dentro de um contexto funcional específico - neste caso, o Recife dos anos 1920, percebido a partir da leitura da imprensa da época.

Assim sendo, nosso foco aqui não será a "história das mulheres”. Queremos nos desviar das hipóteses que tendem a tratar a questão como inversão de polos, como deslocamento de foco para as memórias das mulheres, do feminismo, quer escrevendo histórias em que as mulheres aparecem como que isoladas em ilhas (PERROT apud RAGO, 1998, p. 1); quer contando histórias em que se evidencia o desejo de inversão do jogo na mesa do poder, como se uma alteração desta natureza pudesse resolver a questão.

Ainda segundo Joana Maria Pedro, “convém lembrar que ‘entrar para a história’ tem sido um valor disputado [...] [pois] para muitas pessoas, esta era uma forma de imortalidade” (2005, p. 83). Devemos estar atentos, entretanto, para que a competição por este "valor de imortalidade” seja realizada de maneira a não gerar uma re-exclusão, por exemplo.

Por isso, soam mais interessantes aquelas propostas que tratam o gênero como uma relação, incapaz de ser entendida adequadamente fora de seu contexto, que não deve ser confundido com amarras que impossibilitem a construção de novas relações de gênero, reconfigurando antigas. Ou, nas palavras de Angela Arruda:

[...] teorias relacionais, em que não se pode conhecer sem estabelecer relação entre o tema/objeto e o seu contexto. Gênero é uma categoria relacional, na qual, ao se levar em conta os gêneros em presença,

\footnotetext{
2 Empregamos o termo aqui no sentido de indivíduos e grupos que detêm menos status social e capital econômico, o que acaba resultando em menos poder social e em menor capacidade de movimentar-se dentro da sociedade, constituindo, nos dizeres de Elias “grupos socialmente fracos” (1994, p. 50).
} 
também se consideram as relações de poder, a importância da experiência, da subjetividade, do saber concreto (ARRUDA, 2002, p. 133).

O gênero passa, finalmente, pela verificação, por parte dos(as) pesquisadores(as), de que no campo sociocultural são estabelecidas marcas de diferença que identificam homens e mulheres segundo modelos que não necessariamente encontram correspondente na anatomia/sexualidade: "gênero não está para a cultura assim como o sexo está para a natureza” (BUTLER apud PEDRO, 2005, p. 91), havendo, de uma forma ou de outra, criação de tipos ideais pertinentes ao comportamento e à conduta esperados por/de cada um dos gêneros

Assim, também é preciso evitar hipóteses que tratam a categoria "gênero" como algo estático, a-histórico e monolítico, como se dentro dele não existissem disputas de poder, ou como se todos os indivíduos identificados por um gênero fossem concordantes na definição do que é a categoria (ou como se selecionam seus membros, etc.).

Os problemas de hipóteses, como as acima, é que, tanto no primeiro quanto no segundo caso, isolam a categoria de análise de outras e do contexto funcional em que operam. Ou melhor: isolam os indivíduos dentro do gênero como se eles não se relacionassem a outros indivíduos “fora” do seu gênero, e como se o seu gênero fosse definido internamente, por si mesmo, de uma maneira autoatuante, o que terminaria por reificá-lo em algo externo aos próprios indivíduos.

A respeito da 'reificação' de categorias de análise, Elias tece considerações formidáveis no livro A sociedade dos indivíduos, no qual argumenta que a relação entre os indivíduos e a sociedade, apesar de aparentemente simples e "tranqüila”, esconde várias limitações e dificuldades de exercício prático, porque normalmente “A sociedade é entendida quer como mera acumulação, coletânea somatória e desestruturada de muitas pessoas individuais, quer como objeto que existe para além dos indivíduos e não é passível de maior explicação” (ELIAS, 1994, p. 7), o que conduz os cientistas humanos a uma bifurcação em “T”, onde só é possível escolher um dos lados: ou o indivíduo racional soberano, ou a sociedade como "coisa social” externa aos indivíduos, apesar de que "nenhum dos dois [indivíduo nem sociedade] existe sem o outro” (Ibid., p. 18).

No tocante a gênero em particular, Joana Maria Pedro (2005) lembra-nos que esta categoria de análise tem uma forte carga política e esteve sujeita (ainda está, certamente) a diferentes interpretações ao longo da história, não sendo, de maneira nenhuma, pacífica e homogênea a sua utilização, nem por pesquisadores, nem por ativistas. De maneira 
semelhante a qualquer outro campo, o gênero está sendo constantemente disputado pelos desejos e expectativas dos indivíduos que têm diferentes opiniões a respeito do que ele representa (e quem representa, sobretudo). Como afirma Elias, "O que une os indivíduos não é cimento [...] [eles] se cruzam aos trancos, cada qual perseguindo suas próprias metas e projetos. Vão e vêm como lhes apraz” (Ibid., p. 20).

No que concerne ao valor científico da análise, o problema está relacionado com o valor de memória do discurso historiográfico, que muitas vezes caminhou no sentido de deixar de lado as mulheres: “'entrar para a história’ tem sido um valor disputado [...] [pois] para muitas pessoas, esta era uma forma de imortalidade” (Id., 2005, p. 83). Contudo, a disputa por este valor, pela “imortalidade”, deve ser realizada de maneira a não gerar uma reexclusão, uma inversão. Isto acontece muitas vezes com os(as) cientistas mais preocupados em analisar a sociedade como ela deveria ser, ao invés de tentar aproximar-se de como ela é, buscando uma análise mais congruente com a realidade (nos termos do referido autor).

O gênero passa, finalmente, pela verificação, por parte dos(as) pesquisadores(as), de que no campo sociocultural são estabelecidas marcas de diferenciação que identificam homens e mulheres segundo modelos que não necessariamente encontram correspondente na anatomia/sexualidade, fazendo com que o gênero não seja meramente a "versão culturalista do sexo", posto que, a despeito dos "tipos ideais" criados nos discursos sobre o comportamento/conduta indicados aos diferentes gêneros, a construção desta relação é sempre dinâmica e incompleta, como veremos no decorrer deste artigo.

\section{A função do humor dentro do contexto da imprensa}

Neste artigo, daremos bastante atenção às produções do discurso humorístico presentes nos períodos. Dentro deste tipo de discurso, a seção "Perguntas às senhoritas" e o humor nela envolvido merecem uma destacada atenção. Edivór, jornalista da Pilhéria, tem uma idéia interessante (e que parece ter-lhe rendido bons frutos): criar uma coluna na qual, por meio de versos, faria perguntas às leitoras da revista, que, também em versos, responderiam com cartas a serem publicadas no número seguinte, com menção honrosa para a melhor dentre as respostas.

Com esta estratégia, Edivór esperava que as jovens leitoras de A Pilhéria se sentissem mais envolvidas com a sua produção: liam primeiro a proposta, comentavam com as amigas; enviavam a resposta, aguardavam ansiosas a nova semana e a publicação; liam seus versos na 
revista, comentavam com as amigas; esperavam uma nova revista e um novo mote do colunista; e assim por diante ${ }^{3}$. A coisa toda parece ter acontecido numa atmosfera de seriedade grande o suficiente para que as leitoras cujas respostas não fossem publicadas corressem a escrever cartas para os editores, demandando explicações e porquês para suas respostas não terem ido ao prelo ${ }^{4}$.

No seu estudo sobre as relações de gênero no Brasil durante os anos 1914 e 1940, Besse afirma que "os concursos eram extremamente populares entre as leitoras e tinham bons impactos sobre as vendas das publicações” (1999, p. 30), e iam desde disputas de fotos até contendas poéticas, como no caso d'A Pilhéria. Assim, muitas vezes, do concurso se desprendia um lugar de participação mais regular das leitoras, que ajudavam a construir o periódico que liam - como na seção "Colaboração das Leitoras", da revista A Cigarra (BESSE, 1999, p. 31), e na seção “perguntas às senhoritas”, do nosso exemplo recifense.

Somos levados a crer que naquela "brincadeira” de versinhos uma rede se estabelecia, configurando o seguinte: prestígio para aquelas que conseguiam ver suas respostas publicadas; inveja por parte daquelas cujas respostas não estavam nas páginas da principal revista de variedades da época. Isto se devia, provavelmente, ao fato de revistas semanais como a Pilhéria representarem para os indivíduos da cidade um importante veículo de informação bastante próximo deles, diferente dos jornais, em que a primeira página trazia, invariavelmente, notícias de fora do estado e do País. As revistas não. Elas narravam coisas do cotidiano dos(as) leitores(as), que ajudavam a construir e reconstruir em suas páginas. Ter sua foto ou seu texto publicado nas páginas de um semanário como a Pilhéria trazia, naquela rede específica de "poetisas”, um prazer semelhante ao experimentado, por exemplo, pelo vencedor de uma das regatas de remo (então o esporte de maior prestígio) no rio Capibaribe, pois estes feitos não paravam aí, circulavam muito além dos periódicos (e do meio esportivo, no caso do remo). Tornavam-se exemplos a serem seguidos.

Em estudo sobre as crônicas, Diogo chega a conclusões semelhantes, considerando, em resumo, que:

\footnotetext{
${ }^{3}$ Uma forte evidência a este respeito é o despacho para a senhorita Ivette, na Pilhéria do dia 28 de julho de 1923. Nele, a senhorita confidencia à revista que teme pelo seu namoro caso seja publicada sua resposta à "Pergunta às senhoritas”. O despachante responde que ela não deve temer a perda do namorado, porque "namorado é biscoito... [perde um, vêm dezoito]” (p. 14).

${ }^{4}$ A seção "Despachos” da Pilhéria trazia comentários sobre as cartas que os(as) leitores(as) escreviam para a revista - quase sempre - para perguntar sobre as razões de alguma contribuição sua não ter sido publicada. Na "Despachos" de vários números da Pilhéria, o "despachante” responde às perguntas das senhoritas acerca dos motivos para as suas cartas não terem sido publicadas. Entre os principais motivos estão o "atraso" (entregue depois do fechamento da edição), os "versos quebrados” (sem rima), o "desconhecimento da gramática” e os “erros e métrica” (três versos com 9 sílabas e um com 10 sílabas, por exemplo).
} 
Como veículos de informação, as revistas [os semanários] intervinham no cotidiano da cidade, atuando como porta-vozes da atualidade ao mesmo tempo em que criavam elos identitários com os leitores. [...] Dessa forma podemos atribuir às revistas a tarefa de construir memórias e exercer uma função pedagógica para seus leitores na medida em que as mensagens que procuravam transmitir partiam da coletividade e também atuavam sobre ela, buscando orientar as percepções e as sensibilidades dos leitores a respeito da cidade e seus sentidos (DIOGO, 2005, p. 462; 464).

No tocante às temáticas, os "versos de proposta" 5 do colunista Edivór traziam linhas com base no assuntos que os(as) jornalistas e editores da revista julgavam interessante o suficiente para receber cartas das leitoras. O que, por sua vez, passava, precisamente, pela exploração dos elementos do universo feminino $^{6}$ daquelas mulheres que consumiam o semanário ${ }^{7}$.

Contudo, não devemos esquecer que a Pilhéria - como denuncia o próprio nome - era uma publicação que estava às voltas com o riso: a escolha das temáticas passava, consequentemente, pelas expectativas humorísticas que os editores, redatores e jornalistas nutriam. Falavam de melindrosas e almofadinhas não só porque boa parte dos(as) leitores(as) se enquadrava nestas categorias - ou conhecia pessoas que se enquadravam - mas, e não menos importante, porque estas eram figuras faziam rir a cidade com seus trejeitos modernos.

A “novidade” presente nos comportamentos modernos de melindrosas e almofadinhas é um dos pontos que, segundo Saliba, denunciam a presença de uma desconfiança, de uma inadequação em relação a estes comportamentos, pois é “[d]o contraste, [d]o estranhamento e [d]a ruptura de significados” (2008, p. 21) que surge o riso/sorriso típico do humor. Sendo assim, é razoável supor que os comportamentos expressos pelas melindrosas e almofadinhas eram dignos das anedotas por se colocarem contra o que de tradicional havia na cidade, desviando-se dos hábitos e das práticas tidas como regulares. Isto pode acontecer porque, embora nascidos numa rede $\mathrm{X}$ - que os compele a determinados comportamentos, os quais lhes cerceiam algumas de suas faculdades, desejos e aspirações (ELIAS, 1994, p. 33) -, os indivíduos (neste caso os almofadinhas e as melindrosas) têm sempre à sua disposição (muitas

\footnotetext{
${ }^{5}$ Ou seja, os versos que Edivór usava para instigar as leitoras, convidando-as ao certame poético.

${ }^{6}$ Em outras palavras, dentro do contexto das mulheres de classe média, os elementos que estavam mais próximos do contato, os que eram mais conhecidos.

${ }^{7}$ Uma análise discursiva pode ser feita no que concerne à escolha do título: por que "perguntas às senhoritas”, e não, por exemplo, “aos senhoritos (sic)”? Provavelmente porque os membros do corpo editorial da revista não esperavam que os "senhoritos" (sic) se dispusessem a responder àquelas perguntas. Na Pilhéria do dia 16 de junho de 1923, Edivór é taxativo ao afirmar em uma nota que "nesta edição não pode colaborar marmanjos” (p. 12). Por outro lado, devemos ter em mente que a prática discursiva é algo em movimento dinâmico, que se cria e configura no momento do próprio discurso. Em outras palavras: as matérias da Pilhéria não tinham, meramente, como temática os objetos de interesse dentro de um universo feminino. Elas criavam e configuravam este universo.
} 
vezes no sentido contrário ao da rede em que nasceram) uma mobilidade, resultante do dinamismo próprio da rede, que lhes permite construir uma nova configuração, uma nova rede: "É assim que efetivamente cresce o indivíduo, partindo de uma rede de pessoas que existiam antes dele para uma rede que ele ajuda a formar” (Ibid., p. 35).

Neste contexto específico, o humor adquire um duplo poder: sem perder a sua função de controle, ele suaviza o conflito, amaina os ânimos e permite que se fale das coisas do dia-adia com um distanciamento, como se tratássemos de um capítulo na vida de pessoas distantes. Desta feita, com versos assaborados de breves e suaves, as "representações humorísticas [...] forjam-se nos fluxos e refluxos da vida, no tecido histórico e social - já que cada sociedade cria e inventa seus próprios espaços de repressão e transgressão” (SALIBA, 2008, p. 28), exercendo, sem sombras de dúvidas, um papel de controle a partir do discurso humorístico.

Além do que, boa parte dos(as) “coitados(as)” que apareceram naqueles versos eram figuras públicas ligadas de alguma maneira à revista, o que reafirma tanto a formação de uma rede de sociabilidade entre os(as) que comungam daquelas leituras e daqueles versos humorísticos, quanto da força de atenuação presente neles. Afinal, sempre se poderia dizer algo como: “feio, você? Qual! Era apenas pilhéria!”.

Trocando em miúdos: em algum lugar entre o cotidiano, os versos e o humor da coluna "Perguntas às senhoritas” constituíam parte dos discursos que legitimariam não só os comportamentos e as funções pertinentes aos gêneros, mas as identidades e nomenclaturas dos diferentes tipos da cidade, e mesmo as variações encontradas dentro de um mesmo gênero.

Prosseguindo em nossa análise, temos que as nomenclaturas são centrais para uma coluna como essa, pois o estereótipo é um dos principais expedientes através dos quais funciona o humor (Ibid., p. 16), ao permitir que o destinatário da mensagem humorística resgate rapidamente os significados envolvidos, restabeleça a mensagem e ria. Analogamente, a criação dos estereótipos - e de quaisquer outros procedimentos do humor: anedota, antítese, concisão (Id. ibid.) - traz consigo a formação de identidades e reduções. Algo como “a melindrosa é” ou "o almofadinha é” não traz espaços para variações ou vacilações. A utilização do verbo de ligação "ser” no indicativo restringe o sentido da melindrosa e do almofadinha aos predicativos que se lhes seguem, entrelaçando num sentido só os dois termos da oração.

As identidades, contudo, como alerta Gruzinski (2001, p. 47-50), da mesma forma que inúmeros outros conceitos na história, não são puras: há nelas algo de misturado, indefinido, impreciso, que escorre por entre os dedos, pois “Cada criatura é dotada de uma série de 
identidades, ou provida de referências mais ou menos estáveis, que ela ativa sucessiva ou simultaneamente, dependendo dos contextos” (GRUZINSKI, 2001, p. 53).

Por isso, em determinados momentos, veremos choques entre os comportamentos esperados de homens e mulheres, pois a carga social aplicada sobre eles exige uma plasticidade e um "jogo de cintura” dentro das condições que se lhes ofereciam, o que, com uma frequência considerável, conduz ao destaque de uma ou outra “identidade”, de uma ou outra "função" em diálogo com o ambiente e as pessoas que nos envolvem, pois, certamente, todas estas funções são interdependentes entre si, posto que assumidas pelo mesmo indivíduo em suas relações com outros indivíduos, com os quais intercambiam (ELIAS, 1994, p. 23). Uma função - ou identidade social, em certo sentido - só ganha relevo em relação a outra justamente neste contexto relacional, quando se torna mais urgente ao indivíduo exercer uma dimensão, um aspecto do complexo ser que de fato é. A forma como o indivíduo percebe e exerce sua masculinidade pode variar, por exemplo, de acordo com as outras funções assumidas pelos homens em contextos específicos, que, diante de qualquer mudança, demandam um novo conjunto de características formativas. Capdevilla desenvolveu pesquisas interessantíssimas a este respeito, rastreando as diferentes configurações da masculinidade dentro do espaço temporal entre as (e dentro das) duas grandes guerras: "para os homens a identidade masculina, no decorrer do período do entre-guerras e da Segunda Guerra Mundial, constrói-se primeiramente sobre a identidade do chefe de família e não mais sobre a do soldado [como aconteceu durante a Primeira Guerra Mundial]” (CAPDEVILLA e PEDRO, 2005, p. 87). Analogamente, teremos conflitos e permutas nas vezes em que os significados tradicionais do masculino se percebam ameaçados pelo almofadinha, preso à vida tal como ela se apresenta nos filmes, com o glamour e o gozo, a moda e a velocidade, características que se consideravam femininas.

Dito isto, regressemos ao humor e percebamos que nos significados e identidades produzidos pelos versos cômicos e satíricos percebemos a reafirmação do exposto por Bergson (apud SALIBA, 2008, p. 22): “o riso deve corresponder a certas exigências da vida em comum. O riso deve ter uma significação social”, que neste caso tem a ver com a produção de discursos a respeito do feminino e do masculino. O riso, portanto, não é algo que se desprende do social, mas um item que encontra nele respaldo e diálogo, integrando-o. É um sistema peculiar de comunicação, cujas mensagens seguem um ritmo próprio de codificação, que torna as intenções claras o bastante para os indivíduos nele inseridos (BREMMER, 2000, p. 13). 
Ademais, como se pode ver no filme “A filha do advogado”' há gradações diferentes de almofadinhas, nem sempre contempladas pelos periódicos. Nesse filme, produzido durante o Ciclo de Cinema do Recife ${ }^{8}$, conta-se a história de Heloísa, a 'filha do advogado’ Paulo Aragão, fruto de uma relação extraconjugal dele com Lucinda Correia. Tendo de viajar para o exterior, Paulo pede a seu grande amigo, o jornalista Lúcio Novais (mocinho do filme), que cuide de sua amante e de sua filha, e que traga as duas para viver no Recife. Um amor acontece entre Lúcio e Heloísa, que sofre nas mãos de seu meio-irmão, o vilão Helvécio Aragão. Lúcio Novais é jovem, gosta dos bailes dançantes, veste ternos de cores claras e está sempre com o cabelo alinhado, mas difere bastante de Helvécio Aragão, que reúne as mesmas características que o seu nêmesis, mas de maneira exagerada, o que o aproxima do estereótipo de almofadinha apresentado neste artigo. Desta forma, o estereótipo do almofadinha se constrói no espaço aberto com o excesso, o exagero de que têm receio determinados grupos da sociedade. É preciso modernizar, mas dentro de certos limites.

E aqui a análise de Elias torna-se novamente cardeal. Se pensarmos o almofadinha e/ou a melindrosa como personagens que representam totalidades de indivíduos, estaremos comprando barato a pilhéria dos jornalistas, e incorrendo em uma armadilha teóricometodológica comum nas ciências humanas, qual seja, a de tomar as categorias não como ponto de partida para compreender as relações entre os indivíduos, mas como chave-mestra das relações entre os indivíduos, como se ela pudesse simplesmente resolver as diferenças, igualar as particularidades e equacionar o problema. Ou, para colocar de outra forma, reunir caraterísticas como cuidar da aparência, gostar de dançar e vestir paletós de cores claras não são suficientes para "marcar” alguém como almofadinha (pelo menos não aquele que figura nas caricaturas). Neste breve estudo, entretanto, nos interessamos mais pela força que esse caricaturamento tinha, a ponto de ser exaustivamente explorado - página após página, seção após seção - pelo principal semanário recifense da época, de onde depreendemos que malgrado o humor envolvido na discussão - é inegável o choque que estes personagens causavam no Recife daqueles idos. Dito isto, retornemos a eles.

\footnotetext{
${ }^{8}$ O Ciclo de Cinema do Recife (ou simplesmente Ciclo do Recife) aconteceu entre 1922 e 1931, época em que a cidade acompanhou uma grande profusão de salas de cinema. Neste momento, os artistas locais, como o ator e diretor Jota Soares, voltaram-se para a produção regional de filmes mudos.
} 


\section{Quem eram os almofadinhas e as melindrosas?}

Uma das primeiras aparições dos almofadinhas ${ }^{9}$ na imprensa pernambucana foi no final de 1919, numa matéria de segunda página do Jornal do Commercio da segunda-feira, 10 de novembro, onde eles eram tratados como causadores de confusão que importunavam as moças da região, sobretudo na famosa praia do Carmo, em Olinda ${ }^{10}$.

Segundo o autor, a história dos almofadinhas estava ficando um “caso tão sério” que vinha se tornando tema corriqueiro nas conversas de bonde, como a que ele entreouvira certa vez entre duas senhoras e um menino:

- Eu já tenho até medo de ir a Olinda!

- Por quê?

- Ora, já se sabe. Toda noite se dá ali um barulho por causa de "almofadinhas"...

E um pequeno entrou na conversa:

- Um dia desses vinham dois pela rua do Hospício e todas as moças entraram a baterem as portas.

A crer nos nossos interlocutores, em Olinda - na famosa praia do Carmo - e em Recife, na importante rua do Hospício ${ }^{11}$, os almofadinhas eram figuras certas a perturbar a ordem e gerar confusão, tendo por alvo principal as moças, que deles fugiam. Não temos, entretanto, por meio deste recorte, muitos detalhes acerca de quem fossem, como se vestissem e especialmente o que fizessem estes novos tipos da cidade. Essa forma descritiva se inseria na prática discursiva de um jornalismo menos “intrometido" no cotidiano da cidade durante o final da década de 1910 e o início da década de 1920. Quadro que mudará bastante ao longo dos anos 1920, com a consolidação das crônicas nos jornais e o surgimento de mais semanários. Será somente a partir desta última fonte que nós conheceremos com mais

\footnotetext{
${ }^{9}$ A partir dos relatos de vida de pessoas que viveram no Recife durante os anos 1920 e 1930, pudemos decifrar um pouco melhor a obscura formação da alcunha "almofadinha": diziam eles(as) que os bancos dos bondes antigos eram feitos de madeira, o que deixava as nádegas doloridas depois de tantos vais-e-vens e solavancos; assim, algumas pessoas levavam de casa sua própria "almofadinha" para os bondes. Ao que parece, para as mulheres não havia problema algum no comportamento. Para os homens, ao contrário...

${ }^{10}$ Olinda é uma cidade que fica na região metropolitana norte do Recife. A praça do Carmo é uma área altamente urbanizada; sua ocupação e construção remontam ao século XIX, e têm a ver com o convento do Carmo. A praia do Carmo tem muitas pedras, e um mar com ondas muito fortes, que dificultam o banho de mar. Assim, a utilização da praia pelos(as) recifenses/olindenses no início do século 20 era sobretudo taciturna/noturna (das $16 \mathrm{~h} 00$ em diante), e não tinha no banho de mar seu principal atrativo. Diferente do que acontece atualmente na praia da Boa Viagem (no litoral sul do Recife), por exemplo, que é mais frequentada pelo público nos períodos da manhã e da tarde, e tem no banho de mar um de seus principais atrativos.

${ }^{11}$ A rua do Hospício, localizada no centro da cidade do Recife, é uma área que ao longo do século 20 congregou diversos prédios importantes para a vida cultural da cidade, como a sede do Instituto Histórico e Geográfico (na rua do Hospício desde 1919) e o Teatro do Parque (nesta rua desde 1905). Era, portanto, bastante frequentada pelas classes médias da cidade.
} 
intimidade esses personagens do Recife moderno, especialmente através da já citada Pilhéria, na seção de "Perguntas às senhoritas", como neste mote versificada, de 14 de julho de 1923: “Leitora, não é demais/O que ledes nestas linhas;/Respondei: o que julgais/Dos nossos almofadinhas” ${ }^{\prime 2}$.

As primeiras respostas aos versinhos de Edivór ${ }^{13}$ saíram na semana seguinte (como era mister), no dia 21 de julho. Algumas delas eram bastante duras, como a da Jovita: "Eu julgo do almofadinha/O mesmo que à melindrosa:/Enquanto esta é vaporosa/Aquele é um pelintrinha”; de Maria do Carmo: “Eu julgo que essa gentinha/Merece uma repressão/Pois do modo que caminha/Envergonha a geração”. Outras expressavam encantamento, como as de I. Vianna: “O almofadinha pra mim/É o mais belo espécimen/Que eu tenho visto e adorado/No nosso atual regímen”; de Marina “Nada posso responder/À pergunta apresentada,/Unicamente por ser/Dum almofadinha amada”. Mas a que, para mim, chama mais a atenção, é a da vencedora, Sophia, para quem: "O almofadinha precisa ter/Com o concurso duma vaia/Quem as calça lhe arranque/Substituindo-as por saia”14.

Antes de comentar qualquer das respostas acima, gostaria de acrescentar a matéria que saiu também no dia 21 de julho, e apenas uma página antes, na coluna "O qui nós vê na capitá”. Aqui, o autor, escondido atrás dos matutos Filorenço e Frutunata ${ }^{15}$, critica costumes “esquisitos” da "cidade grande”. Desta vez, o cenário é a festa do Carmo, onde se deu uma confusão “dos diabos”, com almofadinhas e melindrosas (medrosos e medrosas) desembestando-se a correr:

As melindrosa, cumpade,/Corria qui nem viado/E os tás dos armofadinha/Chorava cumo uns danado/Nem corage eles tivero/De se fazere alinhado [...] Garanto qui dessa gente/Não inziste no sertão/Deus queira qui lá não chegue/Povo dessa geração/Pruquê o disastre é feio/Não inziste salvação. ${ }^{16}$

Primeiro as damas. Comecemos pelas respostas das senhoritas. Sophia diz-nos que os almofadinhas merecem ter as calças arrancadas, trocadas por uma saia, ao concurso de uma

\footnotetext{
${ }^{12}$ Perguntas às senhoritas. A Pilhéria. Recife, 14 jul. 1923. p. 8.

${ }^{13}$ Não devemos imaginar, em absoluto, que as respostas das leitoras (ou qualquer contribuição desta natureza) expressassem as idéias oficiais da revista. Na Pilhéria de 7 de julho de 1923, a seção "Despachos" responde a uma senhorita que não conseguiu ter seus versos publicados na seção "Perguntas às senhoritas", afirmando que seus versos não são bons, que eles são tão melindrosos quanto a dona (p. 6).

${ }^{14}$ Perguntas às senhorinhas. A Pilhéria. Recife, 21 jul. 1923. p. 20.

${ }^{15}$ A função dos matutos é bastante interessante no jogo do humor, pois eles retiram do autor - através dos nomes, da linguagem e dos estilos discursivos deles - a proximidade com os eventos, permitindo que ele critique a vida moderna de sua cidade por trás de um “escudo”, que o protege da exposição.

${ }^{16}$ O qui nós vê na capitá. A Pilhéria. Recife, 21. jul. 1923. p. 19. Como se pode perceber, o autor desloca os acentos, retira letras e muda a métrica das palavras para se aproximar do modo de falar dos matutos por ele representados. O que, evidentemente, não deixa de ser uma caricaturização.
} 
vaia. Isto porque eles não se comportavam como "homem”, passando maquiagem, usando roupas finas, etc. - como pudemos observar não só nas descrições textuais, mas nas imagens e representações presentes em fotografias de semanários como A Pilhéria, e na película A Filha do Advogado, do Ciclo de Cinema do Recife.

Como afirma Elias, cada função traz consigo uma série de hábitos que devem ser incorporados pelo indivíduo, estruturando tanto a função quanto o contexto em que ela age: "Cada qual é obrigado a usar certo tipo de traje; está preso a certo ritual no trato com os outros e a formas específicas de comportamento” (ELIAS, 1994, p. 21). No caso dos dois personagens deste artigo, como veremos mais detalhadamente adiante, eles se vestiam, ritualizavam e se comportavam de maneira diferente da esperada por homens e mulheres.

As mudanças na indumentária dos homens recifenses não eram um “privilégio” local. Elas se harmonizavam com as encontradas em outros centros (notadamente o Rio de Janeiro), como descreve Besse: "a rigidez das linhas das roupas dos homens se amenizou, e roupas esportivas e paletós de cores claras tornaram-se mais populares. Os homens passaram a barbear-se e deixaram de usar bengala” (BESSE, 1999, p. 34).

Diferente das senhoritas, o matuto Filorenço não se incomodava tanto com a aparência deles. Ele “pegava raiva” dos almofadinhas porque na hora da confusão, eles se comportaram como covardes, choramingando, sem nem se fazerem "alinhados”, como conviria aos homens. Um abuso assim é demais para ele, que não quer nem ouvir falar de gente assim no seu sertão. Para ele, a coisa estava muito séria. Não havia salvação. O que leva Filorenço a construir esta oposição entre "homens” e “almofadinhas”, entre Recife e o seu Sertão? Segundo Gomes (2003), na ambiência tradicional, cria-se um “modelo de masculinidade a ser seguido. Ressaltam-se as ideias de que o homem de verdade é solitário e reservado no que se refere às suas experiências pessoais, ou, quando muito superficial e prático, direcionado para agir e realizar atividades”(Id. ibid., p. 827). Neste modelo de comportamento não caberiam o choro, a maquiagem, a vaidade dos almofadinhas.

A masculinidade pode variar, por exemplo, segundo outros papéis assumidos pelos homens em contextos específicos, que, numa mudança, demandam um novo conjunto de características formativas. Assim, a 'masculinidade ideal', o 'modelo de homem' são “apenas” representações que se tornaram hegemônicas dentro de um contexto específico.

Logo, como afirma Capdevilla (2005, p. 86-87), a agressividade masculina em relação às "mulheres modernas”, que ganhavam os espaços públicos, não é um dado, mas algo alimentado pela crise de identidade masculina no contexto das guerras. 
Notemos ainda que existe uma dupla identificação envolvendo os almofadinhas: eles são colocados como os representantes daquela atualidade, quer para o "mal” ("do modo que caminha, envergonha a geração" ${ }^{17}$ ), quer para o bem ("É o mais belo espécimen que eu tenho visto e adorado no nosso atual regímen” ${ }^{18}$ ), por apresentarem comportamentos opostos aos encontrados nos homens do sertão, onde os valores tradicionais de masculinidade estariam mais presentes.

Por conseguinte, os almofadinhas - assim como as mulheres modernas, do outro lado $^{19}$ - eram apresentados como seres que desafiavam as categorizações comuns à época, desviando-se para o outro lado, ousando correr o risco de sofrer represálias e censuras por usarem certos elementos característicos do outro gênero. Isso provocava nos outros habitantes da cidade uma espécie de "mal-estar generalizado a respeito da aparente ‘masculinização’ das mulheres e ‘feminilização’ dos homens” (BESSE, 1999, p. 33).

Este estranhamento relaciona-se, portanto, a uma percepção de 'masculinidade ideal' presente no Recife dos anos 1920 (de certo, um fenômeno comum a outros locais e épocas). Este 'modelo de homem' estaria ligado a características diversas das dos almofadinhas. Este 'homem' prezaria pela sobriedade, pela economia de sentimentos, pela seriedade e praticidade, que se mostrariam, inclusive, em suas atitudes, gestos e vestes.

Havia mesmo, segundo, o diário de Mlle XXX, uma divisão entre esses dois tipos particulares de "homem" - o almofadinha e o tradicional: "Domingo 14 - Hoje, dia de regata, estive no Recife. Muita gente, muita alegria, muita algazarra. Almofadinhas, melindrosas e homens... (grifo nosso)"20. Interessante, não? No discurso da autora existirem, separadamente os homens e os almofadinhas. Mas por quê?

\footnotetext{
${ }^{17}$ EDIVÓR; DO CARMO. op. cit.

${ }^{18}$ EDIVÓR; VIANNA, I. op. cit.

19 As mulheres modernas eram de certa forma o contraponto dos almofadinhas: mulheres que exibiam característica daquilo que se pensava ser o masculino. A este respeito, Rachel Soihet argumenta que as coisas aconteceram um tanto diferente do sentido totalizante (universalista, estático e naturalista) criado pelos discursos que resumem as funções e configurações possíveis às mulheres: "fragilidade, recato, o predomínio das faculdades afetivas sobre as intelectuais, a subordinação da sexualidade à vocação maternal” (SOIHET, 2001, p. 3). Para Soihet, estas características só vieram a se difundir e se fortalecer a partir de argumentos da medicina social, no sentido de normatizar os sexos a partir do século 19, época em que a crença nas ciências caminhava na direção de que era possível dissecar, analisar, estudar, descobrir regras gerais sobre e melhorar (praticamente) qualquer coisa. Ao longo dos anos ficou mais claro algo adverso a esta interpretação do conhecimento científico: todo conhecimento é contingente, inclusive a ciência. Em outras palavras, todo conhecimento apresenta resultados que são criados, e não descobertos pelo cientista, que age de acordo com sua relação em configurações como gênero, nacionalidade, família, etc. (esta questão foi bem discutida nas obras de pensadores como Thomas Khun, Karl Mannheim, dentre outros). Reconhecer a contingência do conhecimento - ou seja, reconhecer que ele não é produzido externamente aos indivíduos, mas por eles em suas relações - é um passo importante para reconhecer a historicidade e suas premissas e postulados de verdade, o que, por sua vez, leva ao reconhecimento de que é possível alterá-lo.

${ }^{20}$ Do diário de Mlle. XXX. A Pilhéria, Recife, 20 set. 1924, p. 17.
} 
Além das características já citadas anteriormente, os almofadinhas comportavam-se também de maneira diferente em relação à forma como tratavam as mulheres: "Quarta-feira, 17 - [...] às 15 horas fui à rua Nova. Que impertinência de almofadinhas. Não nos deixam passar sem um olhar, uma indiscrição” (grifo nosso) ${ }^{21}$. Aos homens, segundo esta e outras damas, caberia a iniciativa na conquista, que, entretanto, deveria ser feita docilmente, com respeito. Algo bastante diferente dos almofadinhas, que lançavam olhares e cortejos “impertinentes” às moças que passavam. Pior: a todas as moças, ao que parece.

Finalmente, mas não menos importante, os almofadinhas contavam com uma habilidade que lhes permitia largar na frente nas conquistas das suas consortes prediletas, as melindrosas: eles dançavam o foxtrot, o onestep, o ragtime, o shimmy, o maxixe, e qualquer outra dança (desde que “da moda”, é claro). Como atesta João da rua Nova, na sua coluna vintista "Do "flirt", do "footing”, da rua Nova...”: quando sua admiradora, depois de longa conversa, convida-o à dança, ele secamente responde "Eu não danço, não sou almofadinha”. A dança era, portanto, coisa de almofadinha, que não se importava em perder um pouco da dureza e aspereza masculina em nome de um bom flirt com uma melindrosa. Ao "homem" era preferível - segundo nosso célebre cronista - perder a dama a perder a compostura no remelexo de uma dança.

Em paralelo, as melindrosas ${ }^{22}$ chamavam a atenção também pelo encontro que produziam entre características do masculino e do feminino em um mesmo ser, ofendendo convenções tal qual seus antípodas, os almofadinhas. Ao contrário destes, porém, suas características “masculinas” exerciam atrativo irresistível sobre a maioria dos homens que, como folhas, caíam aos seus pés. Digo, aos seus olhares:

Melindrosa; tens olhos tão ariscos

Concentrando as perfídias requintadas...

Quando as pestanas fechas: são coriscos,

Relâmpagos, trovões, horrorosas trovoadas...

O teu olhar tem raios voluptuosos,

Lembra curtos-circuitos pavorosos

Por detrás da fumaça de um cigarro

\footnotetext{
${ }^{21}$ Idem.

${ }^{22}$ A confecção do nome parte de “melindre”, que, por sua vez, se aproxima de “engodo”, “chiste”, denuncia o que estas mulheres representavam para boa parte dos homens: uma armadilha, cheia de perigo e beleza. Além desta alcunha, chamavam-nas, às vezes, de “borboletas” e "mariposas”, pela suposta leviandade com a qual voavam rapidamente de flor em flor (de homem em homem). A alcunha melindrosa sobreviveu, sobretudo, na linguagem carnavalesca, como um referente das mulheres “de roupas extravagantes e maneiras afetadas”, que se mostra num modelo tradicional de fantasia composto por vestido curto e decotado, tiara, bolsa e cigarro a tiracolo.
} 
É preguiçoso como um boi de carro

Quando tomas sorvete na Bijou ${ }^{23}$

Tens os olhos iguais aos de urubu...

Matreiros,

Carniceiros...

Quando me atinge o teu olhar tão móvel

Faz-me estrago pior

Faz-me estrago maior

Do que um choque funesto de automóvel...

O teu olhar tem gasolina

Oh! Melindrosa amada,

E tem terebentina

Tal qual a manga espada... ${ }^{24}$

Segundo as declarações do próprio M. do P., os versos futuristas que publicava n'A Pilhéria eram uma tentativa de inserir a cidade na discussão desta corrente artística que descrevia as coisas do mundo a partir dos signos de "futuro", de moderno, possuídos por elas. Em Recife, M. do P. enchia suas linhas rimadas com metáforas de “melindrosas”, “automóveis”, “curtos-circuitos”, “cigarros”, “sorvetes” e "gasolina”; imagens que formavam a “cidade-maurícia” naqueles idos de 1923.

Dos versos, tiramos que as melindrosas tinham olhares elétricos tal qual relâmpagos e trovões, partilhando com estes o encanto e o medo que provocavam nos homens; olhares incandescentes como a gasolina; mais potentes que um atropelamento de carro. Enfim: olhos que, por mais perigosos que fossem, não podiam ser evitados pelos homens, que a elas se entregavam.

Não podemos dizer, entretanto, que as melindrosas fossem tipos simples, pois ao mesmo tempo em que lançavam olhares e tomavam iniciativa na conquista (o que tradicionalmente cabia aos homens), elas mantinha viva a magia da sedução - ainda que atrás de fumaças de cigarro, pois o ato de fumar também era considerado próprio do masculino ${ }^{25}$-,

\footnotetext{
${ }^{23}$ A Bijou era uma loja do centro da cidade, bastante visitada pelos membros da classe média, que lá iam para fazer compras, flertar e fazer o footing - espécie de caminhada, de passeio, em que homens e mulheres colocavam suas melhores roupas, flertavam, tomavam sorvetes e assim por diante.

${ }^{24}$ M. do P. Melindrosa: versos da escola futurista. A Pilhéria, Recife, 2 jun. 1923, p. 12.

${ }^{25}$ Susan Besse (1999, p. 33) argumenta, baseada no personagem Viviano, composto por João da rua Nova para a revista fluminense Vida Moderna. Numa das crônicas, Viviano exprimia sua tristeza ao ver uma amiga fumando, pois "não só [achava] que era de mau gosto que as mulheres imitassem hábitos masculinos, mas também que o cheiro da fumaça anulava a doçura do hálito feminino”.
} 
não se descuidando dos seus encantos femininos, como atesta a dupla de versistas Jeff e Mutt $^{26}$ :
Amigo Jeff, atenção
No que lhe vou perguntar
Quero sua explicação
Para o caso elucidar
Porque é que as melindrosas
Vivem sempre rebicadas
Andam todas perfumosas
E de blusas decotadas? ${ }^{27}$

A pergunta de Mutt ao amigo Jeff vem bem a calhar, pois rebicadas pelos rouges e batons, perfumadas, decotadas, com olhares lânguidos, elétricos, potentes, incendiários, quem podia resistir às melindrosas? Bem, muita gente, ao que parece.

Como era de se esperar, moralistas e tradicionalistas não faltaram para não só resistir, mas condenar as práticas das melindrosas, e representá-las como tolas, indecentes, perigosas, levianas... Um breve retorno a "perguntas às senhoritas”, com a qual abrimos estes trabalhos, já deve ser o bastante para termos uma idéia de como se davam as coisas:

Como julgo as melindrosas?

Bem tolas e muito fúteis

Julgam-se deusas, formosas,

Quando são seres inúteis ${ }^{28}$

Lilaz

É inegável o tom de rancor nos versinhos de Lilaz. Provavelmente porque ela não fazia parte do rol de melindrosas. De qualquer forma, para ela, a inutilidade das melindrosas vem justamente das características tão prezadas por elas em sua busca por beleza, que para sua nêmesis seriam tão somente futilidade e tolice, posto que vazias de conteúdo. Neste contexto, é preciso lembrar que muitas daquelas que respondiam às perguntas eram certamente melindrosas, cujas ocupações cotidianas passavam pela leitura de semanários modernos como A Pilhéria. Essas mulheres elogiavam as suas colegas e a si mesmas de maneira muito clara, defendendo que, ao contrário do que se murmurava nas ruas da cidade, as melindrosas seriam seres cheios de pureza, que com nada se importavam, a não ser amar

\footnotetext{
${ }^{26}$ A seção “perguntas de Mutt, respostas de Jeff” era tão tradicional quanto a “perguntas às senhoritas”, além de ter uma estrutura e abordar questões semelhantes. Porém, em Jeff e Mutt, o mesmo redator encarnava as duas personagens, o que lhe dava maior controle das respostas.

${ }^{27}$ MUTT. Perguntas de Mutt e respostas de Jeff. A Pilhéria, Recife, 30 jun. 1923, p. 14.

${ }^{28}$ LILAZ. Perguntas às senhoritas. A Pilhéria, Recife, 7 jul. 1923.
} 
As melindrosas, leitores,

São seres feitos de encantos

Vivem de sonhos, de amores,

E são puras como os santos...

Litinha L. ${ }^{29}$

Eu como sou melindrosa

Só posso assim me expressar:

Acho que vim de uma rosa

E o meu lema é só: amar!

Ignez $^{30}$

Os discursos criados por Litinha e Ignez - que se confessa melindrosa - ligam-se com a romantização desta personagem, que, ao mexer com os hábitos das mulheres de sua época, tem por fito um dos objetivos mais tradicionais do feminino: o amor. Era em nome dele que as melindrosas se enfeitavam e iam às ruas com cigarros nas bocas. Aquilo sobre que os(as) mais conservadores(as) discordavam é que, ao invés de ajudarem o amor, as práticas destas jovens o ameaçavam. Logo, a discussão passava sobremaneira pelas diferentes compreensões que uns(as) e outras tinham a respeito desta emoção, o que, a seu próprio modo, tinha a ver com o casamento e a família como finalidade (ou não) desta emoção.

Este ponto é muito importante para a nossa análise e merece uma breve digressão, pois ele é uma evidência que nos permite entender melhor o insight segundo o qual as relações estabelecidas dentro do contexto são carregadas de dinamismo, e não decorrentes linearmente das necessidades dos indivíduos que dele participam (ELIAS, 1994, p. 42-43). Embora o objetivo, dentro das duas redes menores ( $\mathrm{X}$ - melindrosas; $\mathrm{Y}$ - mulheres tradicionais ${ }^{31}$ ), fosse alcançar o amor, a forma como se portavam os indivíduos dentro delas era particularmente diferente. Enquanto as mulheres em $\mathrm{X}$ tendiam a reforçar a sua beleza com elementos modernos, que usavam de maneira pró-ativa para conquistar os homens, as mulheres em Y achavam que o correto era cultivar uma beleza mais sutil, que cativasse os homens pela pureza e recato. Neste sentido, as mulheres em Y passam a ver o comportamento das

\footnotetext{
${ }^{29}$ LITINHA L. Perguntas às senhoritas. A Pilhéria, Recife, 7 jul. 1923.

${ }^{30}$ IGNEZ. Perguntas às senhoritas. A Pilhéria, Recife, 7 jul. 1923.

${ }^{31}$ O emprego do termo “tradicionais” aqui é muito delicado, pois, como já expressamos na nota 18, a associação entre mulheres e características como recato, predomínio das faculdades afetivas sobre as intelectuais e subordinação da sexualidade à vocação maternal (SOIHET, 2001, p. 3), é uma construção histórica recente. Entretanto, entendemos que ele pode ser utilizado aqui sem grandes problemas por dois motivos: 1) à medida que as melindrosas são identificadas como modernas (inclusive por elas mesmas), é razoável apontar suas "opositoras” como tradicionais - além do que, no transcorrer do texto, veremos que em outros periódicos as "melindrosas” eram chamadas de "mulheres modernas"; 2) confiamos nas palavras de Eric Hobsbawm e Terence Ranger(1984), quando eles afirmam que as tradições não precisam de séculos para se afirmarem - havendo algumas que se consolidam com bastante rapidez -, pois elas estão mais ligadas à temporalidade, à rotina e à ritualística, do que ao tempo efetivamente transcorrido. Isto porque as tradições não precisam ser coisas do passado, elas precisam “simplesmente” evocar e revestir-se de um passado que as legitime (1984, p. 9).
} 
mulheres em X - marcadamente diferente do seu - como perigoso a partir do momento em que ele começa a funcionar, ameaçando as mulheres em Y de conseguirem seus objetivos, como vinham fazendo desde então.

Alhures, não era somente no humorismo d'A Pilhéria que saíam críticas às melindrosas. Antes de passarmos a essa discussão, contudo, é preciso lembrar que melindrosa - tal qual almofadinha - era apenas uma das formas como estas jovem cheias de novidades eram chamadas. Talvez, o termo tenha vingado por elas se terem afeiçoado a ele, mas o que acontecia é que havia quem preferisse chamá-las simplesmente de “mulheres modernas”.

Estabelecendo uma ponte entre o semanário e os outros periódicos, temos que as mulheres modernas reuniam características bastante semelhantes às das melindrosas, como mostra este poema de página inteira da Pilhéria, escrito por Fernando Burlamaqui.

"Mademoiselle de tudo sabe,

De tudo sabe um bocadinho,

Dança com arte,

Canta e recita,

Em qualquer dia, em qualquer parte,

Salta do Bond em movimento,

E também gosta de um cigarrinho.

\section{$[\ldots]$}

Dizem que ela é isso e aquilo

as línguas vis... as línguas más.

Eu francamente não acredito

E acho mesmo que isso é demais...

É, entretanto, moça moderna,

- isso mais de um rapaz

Isso se vê diariamente,

Não é portanto caso esquisito

Não é das coisas fenomenais

É, entretanto, moça moderna...

Quando sobe no Bond mostra a perna,

Tem perna grossa, sonha casar...

Já arranjou um namorado,

Todo apertado,

Que quando anda pela rua, treme,

Que usa creme,

Unhas bonitas e pontiagudas,

Uns óculos grandes de tartaruga,

Fala baixinho,

Afeminado...

E quando

Mademoiselle Bonitinha passa

Toda pintada,

Bataclanisada, 
Pela rua,

Num vestido finíssimo de cassa,

Cheia de encanto, sedução e graça,

O povo todo perde o juízo.

Parece Eva no paraíso.

Quase vestida e quase nua ${ }^{32}$.

Assim como as descrições das senhoritas sobre as Melindrosas, a de Burlamaqui envolve a dança, o canto, o entendimento das coisas modernas, os hábitos masculinizados, o cigarro, a roupa curta e decotada, que, entretanto, não as eximia de querer amar e casar.

Se no semanário a Pilhéria o tom é quase sempre humorístico - seja na crítica, seja no elogio -, nos jornais a coisa não é bem assim. Neles, mesmo em poemas e crônicas (seções "mais leves”, por sua temática e linguagem), o tom é sério, acusatório. Comparemos o poema acima a este, do Jornal do Commercio de 1921:

Ó, sociedade incongruente, Que à vã moral te insinuas, Olha o palude absorvente,

Da corrupção que há nas ruas

Pensa no atroz sacrifício

De tanto lar infeliz, Cheio de "flores de Vício" Porque o mundo nada diz!

Oh! As mulheres modernas!

Glórias de bistre e carmim...

Colo nu, em cruz as pernas...

- Mundo, é próximo o teu fim!... ${ }^{33}$

Diferente de Burlamaqui, que usa a mulher moderna como um personagem em um poema leve sobre a cidade e seus tipos, Costa constrói um poema extremamente crítico e sisudo do que considera o mundo moderno, que compreende como incongruente (1.1), imoral (l. 2) e corrupto (1.4), tomando como exemplo destas mazelas os vícios dos lares infelizes criados a partir das mulheres modernas, que não mais atentariam para a moral e os bons costumes, por mostrarem nus os seus colos (1. 11) e cruzadas suas pernas (1. 11). Essas mudanças - no exagero do autor - seriam um sinal da proximidade do fim do mundo.

As variações na construção do mesmo gênero discursivo podem ser entendidas através dos próprios recursos estilísticos utilizados pelos autores: versos livres em métrica e organização estrófica (Burlamaqui), contra versos presos a uma rima interna (1:3/2:4), e com a previsível organização estrófica de quatro versos (Costa); linguagem mais próxima do

\footnotetext{
${ }^{32}$ BURLAMAQUI, F. Número 3. A Pilhéria, Recife, 15 nov. 1924, p. 41.

${ }^{33}$ COSTA, A. Trovas de Hoje. Jornal do Commercio, Recife, 18 mar. 1921.
} 
coloquial, com rimas mais simples e utilização de uma espécie de refrão ("É, entretanto, moça moderna,”), versus linguagem rebuscada e metafórica ${ }^{34}$. Neste sentido, as distintas configurações destes discursos passavam pelo conservadorismo/modernismo a que se filiavam os autores: enquanto Burlamaqui chega a defender as mulheres modernas das línguas ferinas, Costa concorda com estas mesmas línguas e aponta as damas como principais responsáveis pelo descompasso para o qual se encaminhava o mundo. A repressão de homens como Costa conecta-se, então, com o entendimento de que a modernização leviana das mulheres ameaçaria os pilares da Civilização Ocidental, notadamente a família, que agora deveria se reassentar devido às práticas das mulheres modernas. Não podemos deixar de notar que os almofadinhas recebiam um tratamento mais brando: mesmo quando criticados, não se associava diretamente seu comportamento com os problemas mais amplos que os indivíduos percebiam como típicos de sua época. A identificação entre estes problemas e as melindrosas pode ser percebido dentro do próprio contexto, no qual os homens detinham maior poder, o que lhes permitia, bem ou mal, esquivar-se de parte (senão de toda) a responsabilidade. Também neste caso, entretanto, a valorização do moderno depende dos valores envolvidos na troca, pois, muito embora se exija das mulheres uma modernização, ela deve ocorrer no sentido da higienização e não no tocante a uma reconfiguração dos hábitos e costumes, sobretudo dos mais próximos ao casamento e ao amor.

Os críticos temiam que as que (sic) cultivavam a nova imagem da mulher independente, ousada e sexualmente provocante sofreriam uma revolução de consciência que ameaçaria profundamente a família; temia-se também que as mulheres não pudessem abraçar a moralidade do mercado sem que isso levasse o "materialismo" a triunfar sobre os "valores humanos" na esfera pessoal (1999, p. 37-40).

Como dissemos há pouco, por trás destes discursos escondia-se um desejo dos homens de manterem as mulheres dentro dos parâmetros de controle tradicionalmente exercidos por eles dentro do modelo de sociedade rural-patriarcal, que até bem pouco tempo era vigente no contexto pernambucano. Neste caso, temos uma relação diferente da expressa anteriormente, posto que, no modelo anterior, as mulheres em $\mathrm{X}$ e $\mathrm{Y}$ gozavam mais ou menos do mesmo poder e tinham um objetivo comum, embora percebessem de maneira distinta o caminho até

\footnotetext{
${ }^{34}$ É mister lembrar que na década de 1920 o Brasil se via, resumidamente, entre três movimentos artísticoliterários, que procuravam fazer-se hegemônicos: parnasianismo, simbolismo e modernismo (em todas as suas vertentes). No caso do Recife, embora ainda encontremos poemas com inspiração e organização estrutural simbolista, a maioria tende a conter elementos do parnasianismo (ênfase na estrutura e na métrica, linguagem rebuscada/erudita, etc.) ou do modernismo (verso livre, linguagem mais simples, etc.). Para maiores informações sobre a discussão, procure BOSI, Alfredo. Historia concisa da literatura brasileira. 42. ed. São Paulo: Cultrix, 1999.
} 
este objetivo. Aqui, os indivíduos em Z (homens, sobretudo) têm desejos ambíguos, quais sejam, a modernização do comportamento das mulheres sem que isto ameaçasse a sua posição, seu poder e seus privilégios dentro do contexto a que estavam habituados, e para tanto, valiam-se dos dispositivos mais diversos. Contudo, sua posição em relação aos indivíduos em $\mathrm{X}$ e Y era diferenciada por uma elevação, já que possuíam mais poder, o que lhes garania maior capacidade de manobra (ELIAS, 1994, p. 50)

Seja como for, as resistências dos homens - e de alguns grupos entre as mulheres ${ }^{35}$ são indicativos da força e presença que as novas mulheres tinham naquele momento, o que estava fortemente ligado às mudanças nas relações sociais, provocadas pelo contato com invenções modernas, como o rádio, o bonde, o cinema, etc., que demandavam novas formas de ser e estar no mundo. A configuração do contexto anterior, em que haviam nascido e haviam sido educadas, já não mais cabia a estas mulheres: tratava-se de uma configuração que não lhes dizia como lidar com as mudanças de uma geração para a outra, que não lhes dizia como se portar diante dos namoros de automóvel ou das seduções cinematográficas.

É preciso reconfigurar, rearranjar, de maneira que se possa lidar com as novidades. Esta urgência é, bem ou mal e apesar das discordâncias, percebida por ambos os autores. Eles não discutem que as mulheres modernas estavam "dando o que falar" e tomando conta da cena da cidade, sem nem se importarem - as melindrosas - com as críticas. Como diz Burlamaqui, "Isso [as mulheres modernas] se vê diariamente, não é, portanto caso esquisito, não é das coisas fenomenais”.

Nesse jogo de disputas entre o moderno e o tradicional na construção dos gêneros, as críticas mais pesadas vêm dos intelectuais católicos que escreviam nos periódicos, não apenas clérigos, mas católicos e católicas. Rever esta participação é, porém, um processo muito delicado, pois, apesar da presença de intelectuais confessadamente católicos em setores importantes do Jornal do Commercio, por exemplo, e embora estes intelectuais provavelmente tivessem condições de influenciar a inserção de colunas religiosas no periódico, nele permaneceram as seções mais “modernas”, o que aponta para uma abertura “editorial” na direção de outras temáticas não necessariamente afirmativas da opinião oficial do jornal, mas que nele se reconheciam como dotadas de um valor-notícia que justificava sua publicação.

\footnotetext{
${ }^{35}$ É preciso relembrar o que já dissemos na introdução: o conceito de gênero - como qualquer outra categoria não é o sinônimo de uma série de pessoas agrupadas segundo masculinidade/feminilidade/homossexualidade por meio de uma homogeneidade de interesses, aspirações e compreensões. Muito pelo contrário. As relações que se desenvolvem dentro do mesmo gênero, como exemplifica a já mencionada Joana Maria Pedro (2005, p. 81), na sua leitura das "diferencialistas" e "essencialistas" dentro do movimento feminista de "segunda onda" (p. 81), têm a ver com aspirações individuais (ou de um subgrupo), que nem sempre estão de acordo com as da maioria.
} 
Para permanecer ainda com o Jornal do Commercio, nós temos, em 1921, na seção “Meu Diário”, de Salomão Figueira (sob o pseudônimo S.), à época o diretor do jornal, a publicação de uma matéria em que se faz coro à Sacra Propediem ${ }^{36}$, com a qual se criticam as danças, as paixões e as mulheres modernas ${ }^{37}$. Ao contrário do que poderíamos esperar, apenas alguns dias depois saiu uma matéria do mesmo Salomão Figueira, novamente no "Meu diário”, sobre o primeiro casamento anarquista no Brasil, no qual o autor faz muito mais descrições do que análises ${ }^{38}$. Esse tema - do casamento anarquista -, é inevitável pensar, daria "pano pra manga” para que o diretor e jornalista discutisse maus comportamentos anticristãos e modernos, não? Ele, entretanto, não toma essa posição. O que teria mudado na cabeça de Salomão? Aparentemente, nada. E muita coisa.

Como acentua Fairclough (2001, passim), a leitura das construções dos discursos deve passar não só pela linguagem professa nos textos, mas por suas condições de formação, que envolvem elementos técnicos e socioculturais. A então aparente mudança na forma de pensar do autor pode ser lida pelo seguinte viés: a crítica de Salomão Figueira no Jornal do Commercio ou de Castro n'A Pilhéria são extremamente “despersonalizadas”, dirigindo-se às dançarinas modernas, às mulheres modernas. Uma crítica ao casamento anarquista teria de passar, necessariamente, por um “ataque” aos nubentes. A dúvida, porém, permanece: por que não criticá-los?

Ao que parece, porque os nubentes, as melindrosas, os almofadinhas eram também membros de uma classe média urbana, tal qual os jornalistas. E mais: o pertencimento os(as) colocava como potenciais consumidores(as) dos periódicos. O elogio e a crítica mais personalizados precisavam ser muito bem ponderados, pois, para além da frieza das páginas do jornal, é bastante factível que as melindrosas, almofadinhas e afins, frequentassem as mesmas redes que os editores, ou fossem, quiçá, integrantes do mesmo núcleo familiar. Isto porque a função de jornalista é apenas uma das exercidas dentro do contexto. Em outras, eles eram pais, irmãos, primos, namorados, noivos, que se relacionavam com filhas, primas, namoradas, noivas, as quais, em outro lugar, poderiam ser melindrosas, modernas. Assim, o inegável poder discursivo da imprensa tinha de ser utilizado com todo o cuidado.

\footnotetext{
${ }^{36}$ Esta encíclica papal é, grosso modo, uma crítica aos usos que os “modernos” têm feito de São Francisco de Assis. Entretanto, como é comum às encíclicas - ainda mais naquela época -, está envolvida em um certo hermetismo teológico e filosófico não tão acessível aos populares. Ela está disponível em: <http://www.vatican.va/holy_father/benedict_xv/encyclicals/documents/hf_ben-Xv_enc_06011921_sacrapropediem_en.html>. Acessi em : 18 abr. 2008.

${ }^{37}$ S. Meu diário. Jornal do Commercio, Recife, 2 fev. 1921, p. 8.

${ }^{38}$ S. Meu diário. Jornal do Commercio, Recife, 23 fev. 1921, p. 8.
} 
Outro bom exemplo para analisar as nuanças nos discursos dos jornais é a "Seção Religiosa”, em que os jornalistas católicos criticavam vários dos comportamentos modernos. Sobretudo na segunda metade da década, encontramos matérias nesta seção em que os leitores são alertados para os perigos da má imprensa ${ }^{39}$, e os jornalistas são chamados a se preparar diante das dificuldades e bem orientar seus leitores ${ }^{40}$. A construção de uma má imprensa, segundo a primeira matéria, teria a ver com os periódicos que publicavam notícias ofensivas à religião e aos bons costumes, bem como os que pregavam doutrinas contrárias ao catolicismo. Contudo, a forma de efetivar a classificação entre "boa” e "má” imprensa não era tão simples.

Avancemos mais num caso específico: durante aquela época, discutia-se bastante se os cabelos curtos das mulheres - à la garçonne ${ }^{41}$ - retiravam ou não a beleza e a feminilidade das mulheres, deixando-as parecidas com os homens. A maioria dos(as) tradicionalistas argumentava que sim, que aqueles cabelos masculinizavam as damas e constituíam uma ameaça à moral e aos bons costumes. A seguir rigorosamente os jornalistas católicos, reconheceríamos como "má imprensa” um periódico que publicasse matérias elogiosas do cabelo à La garconne, não?

Se assim fosse, o próprio Jornal do Commercio não escaparia de ser “má imprensa”, pois em 11 de janeiro de 1925, Coelho Netto usou esse veículo para publicar, na seção de variedades "Literatura, Sciencias e Artes”, a tradução de um artigo da norte-americana Mary Parsons, no qual a autora defende o cabelo à la garçonne, afirmando que ele é uma tradição tão antiga que remonta à velha Roma: “quando alguém vos disser que este penteado vos masculiniza, respondei que já tem alguns milhares de anos. Entretanto, o cabelo "à la garçonne” ganha cada vez mais popularidade" ${ }^{42}$. Assim, o mesmo argumento discursivo - de legitimidade e correção ligados à antiguidade, à tradição - pode adquirir tons e atribuições distintas, de acordo com a construção feita pelo(a) autor(a) dentro do seu texto. Tudo depende dos contextos em que ele é lançado, pelos indivíduos que participam da sua publicação e da sua recepção.

\section{9 - As “páginas femininas” e as mudanças no contexto}

\footnotetext{
39 Seção Religiosa. A boa imprensa. Jornal do Commercio, Recife, 3 jan. 1925, p. 3.

${ }^{40}$ Seção Religiosa. O jornalismo atual. Jornal do Commercio, Recife, 7 jan. 1925, p. 3.

${ }^{41}$ Esta terminologia tem a ver com garçon, que quer dizer rapaz em francês. Assim, tem-se algo como "o cabelo à moda do rapaz”, “cabelo com corte de rapaz”.

42 PARSONS, M.; NETTO, C. O cuidado com o cabelo “à la garçonne”. Jornal do Commercio, Recife, 12 jan. 1925, p. 5.
} 
A aparente contradição no editorial do Jornal do Commercio continuou conforme avançaram os anos, e se "agravou” com a inserção da posteriormente bem-sucedida "Página Feminina"43, ainda em 1929. As divergências, contudo, pareciam estar dentro da "normalidade” para o jornal, desde que, evidentemente, cada grupo respeitasse seu nicho de publicação.

Ao longo de 1929, as matérias católicas a respeito da crise com a modernidade continuam firmes e fortes, com o destaque para as publicações nas quais as mulheres eram instigadas (e responsabilizadas) a bem educarem suas crianças, defendendo-as dos perigos do modernismo ${ }^{44}$; e os homens, a reforçarem, no âmbito familiar, a sua autoridade "tão ameaçada por doutrinas subversivas de toda ordem social e religiosa”, com o resgate do argumento da “autoridade divina”, espécie de concessão de autoridade por Deus aos seus representantes na terra ${ }^{45}$.

Paralelamente, nós teremos as maiores defesas das coisas modernas justamente nas “páginas femininas” dos diferentes periódicos, mas com um destaque maior para o Jornal do Commercio. De uma maneira geral, as matérias lá publicadas caminhavam no sentido de contestar os discursos tradicionais, que procuravam submeter as mulheres a uma naturalização permeada por elementos como timidez, doçura, romantismo, como vimos nas páginas anteriores.

Desta forma, diferente dos anos 1920, na década seguinte as melindrosas e modernas receberão o apoio/a crítica de intelectuais que, da sua posição de poder dentro dos periódicos, os utilização como instrumento para a promoção de discursos acerca de práticas que desde antes já se verificavam na cidade. Os almofadinhas/modernos, por outro lado, não terão mais o mesmo destaque nas páginas dos periódicos. Quer por um possível rearranjo provocado na masculinidade com a crise de 1929 e a sombra da beligerância nos anos posteriores, quer por a imprensa recifense ter-se tornado palco para temáticas mais sérias, depois do movimento revolucionário de 1930, a nova década se inicia sem semanários nem revistas, fechando jornais por motivos políticos e outros sendo vendidos a grupos do Sul. Tudo isto contribuiu para modificar o contexto em que vivam os indivíduos durante a década de 1920. Estas temáticas, contudo, ficam para outro artigo.

\footnotetext{
${ }^{43}$ A "Página Feminina” era um espaço dentro do Jornal do Commercio para que as mulheres discutissem temas de seu interesse. Tanto a redação quanto a editoração ficavam a cargo das jornalistas do periódico.

${ }^{44}$ COIMBRA, A. P. A religião como salvação das crianças: o perigo do modernismo. Jornal do Commercio, Recife, 19 jan. 1929, p. 5.

${ }^{45}$ PEREIRA, A. O culto da autoridade. Jornal do Commercio, Recife, 19 out. 1929.
} 
Podemos dizer então que 'almofadinha' era uma alcunha pejorativa dada aos homens que se vestiam com roupas claras, usavam rouge, gostavam de dançar e de flertar com as mulheres. De maneira semelhante, 'melindrosa' era igualmente pejorativo e estava ligado às mulheres que não guardavam o decoro, que se atiravam sobre os homens, que deixavam curto o seu cabelo, etc. Deste modo, ambos os 'personagens' tomavam existência a partir da enunciação de um discurso que percebia papéis naturalizados para homens e mulheres, e percebia em alguns elementos do moderno uma ameaça a esta configuração tradicional. Com efeito, o que mais 'assustava', nestes casos, eram os deslocamentos provocados por estes dois personagens, que assumiam características tradicionalmente identificadas como pertencentes ao seu duplo: os almofadinhas adquiriam características consideradas femininas, e as melindrosas assumiam características consideradas masculinas.

Assim, a existência destes dois personagens dentro dos periódicos da época demonstram disputas pelo poder de reorganizar, de reconfigurar o contexto em que se insere, no caso específico, o de relações de gênero. Ao contrário do que alguns(as) autores(as) da época diziam, não havia nada de natural (ou pelo menos nada de estritamente natural) nas construções de gênero que propunham. Como procuramos demonstrar ao longo do artigo, o posicionamento e a construção do almofadinha e da melindrosa só passaram a existir conforme os próprios modelos tradicionais de gênero foram sendo construídos, numa relação de interdependência. Neste sentido, o tipo era não só um fenômeno novo, moderno, ligado aos eventos mais recentes, como também o era o 'homem ideal'; o mesmo valia para as melindrosas. O processo de configuração, de ordenação das categorias dentro do contexto é interdependente, já que o 'homem ideal' só existe ao mesmo tempo em que o almofadinha, pois, se assim não fosse, não existira distinção, mas identificação de dois tipos diferentes, o que as torna não só interdependentes, mas históricas.

Isto, por sua vez, demonstra a não-existência de um norte ideal e natural a ser seguido. Do contrário: os Standards, os Defaults - como os(as) antigo(as) recifenses já percebiam são meramente criações que em dado momento se tornaram hegemônicas. E assim, com a desnaturalização destas categorias (desnaturalização alimentada por exemplos históricos concretos), esperamos modificar a nossa percepção no presente para a discussão e a modificação de questões semelhantes, tendo em vista melhorar o bem-estar daqueles(as) que enfrentam preconceito por não se adequarem aos Standards, aos defaults atuais. 


\title{
MELINDROSAS AND ALMOFADINHAS: gender figurations in Recife in the 1920's
}

\begin{abstract}
The aim of this paper is to analyze the configuration of the gender relations in Recife, during the 1920s, athwart two stereotype-characters that appeared in the press discourses: the melindrosa and the almofadinha. These characters exemplify an opening in the behaviors standardized in the gender relations, what exposed them to critics and jokes. This work analyzes two newspapers of different typologies (the Jornal do Commercio and the magazine a Pilhéria) throughout Elias' figurational sociology, discourse analysis and the theories about gender relations. Hence, this work aims at contributing to the discussions about gender, adding new historical elements that can help to review daily prejudices.
\end{abstract}

Key-words: Gender- Press- Discourse

Referências bibliográficas

ARRUDA, A. Teoria das representações sociais e teorias de gênero. Cad. Pesqui., São Paulo, n. 117, 2002. Disponível em:

$<$ http://www.scielo.br/scielo.php?script=sci_arttext\&pid=S0100-

15742002000300007\&lng=\&nrm=iso>. Acesso em: 29 out 2008.

BESSE, Susan. Modernizando a desigualdade: reestruturação da Ideologia de Gênero no Brasil 1914-1940. São Paulo: EDUSP, 1999.

BREMMER, Jan. Uma história cultural do humor. São Paulo: Record, 2000. Disponível em: $<$ http://books.google.com/books?hl=pt-

BR\&lr=\&id=zqOLop3SVlwC\&oi=fnd\&pg=PA5\&dq=hist\%C3\%B3ria+humor\&ots=nzyk7sn Mk2\&sig=WK2vQeK9orfKrGLWIAG0rxY-1S4>. Acesso em: 1 jul. 09.

CAPDEVILA, L.; PEDRO, J. M. As guerras na transformação das relações de gênero: entrevista com Luc Capdevila. Estudos Feministas, Florianópolis, 13(1): 216, janeiroabril/2005. Disponível em: <http://www.scielo.br/pdf/ref/v13n1/a06v13n1.pdf>. Acesso em: 20 jul. 2009.

DIOGO, M. O moderno em revista na cidade do Rio de Janeiro. CHALHOUB, C., NEVES, M., PEREIRA, L (Orgs.). História em cousas miúdas: capítulos da história social da crônica do Brasil. Campinas, SP: UNICAMP, 2005.

ELIAS, Norbert. A sociedade dos indivíduos. Rio de Janeiro: Jorge Zahar, 1994.

FAIRCLOUGH, Norman. Discurso e mudança social. Brasília: UNB, 2001. 
GOMES, Romeu. Sexualidade masculina e saúde do homem: proposta para uma discussão. Ciênc. saúde coletiva, São Paulo, v. 8, n. 3, 2003. Disponível em: $<$ http://www.scielo.br/scielo.php?script=sci_arttext\&pid=S141381232003000300017\&lng=\&nrm=iso $>$. Acesso em: 30 out 2008.

GRUZINSKI, Serge. O pensamento mestiço. São Paulo: Companhia das letras, 2001.

HOBSBAWM, Eric; RANGER, Terence. A invenção das tradições. 3. ed. Rio de Janeiro: Paz e Terra, 1984.

IBGE. Anuário estatístico do Brasil (1936). Rio de Janeiro: IBGE, v. 2, 1936.

LUCA, Tania de. História dos, nos e por meio dos periódicos. In: PINSKY, Carla. Fontes históricas. São Paulo: Contexto, 2005.

PEDRO, J.M. Traduzindo o debate: o uso da categoria gênero na pesquisa histórica. História, São Paulo, v. 24, n. 1, 2005. p. 77-98. Disponível em:

$<$ http://www.scielo.br/scielo.php?script=sci_arttext\&pid=S0101-90742005000100004>. Acesso em: 24 jun. 09.

. Epistemologia feminista, gênero e história. In: PEDRO, J.; GROSSI, M. (orgs.). Masculino, feminino, plural. Florianópolis: Ed. Mulheres, 1998.

SALIBA, Elias. Raízes do riso: a representação humorística na história brasileira: da belle époque aos primeiros tempos do rádio. 3. ed. São Paulo: Companhia das Letras, 2008.

SOIHET, Rachel. Formas de Violência, relações de gênero e feminismo. Rio de Janeiro, 2001. Disponível em: <http://www.historia.uff.br/nec/textos/text34.PDF>. Acesso em: 14 abr. 2009. 